\title{
Current Space Station Experiments Investigating Component Level Electronics Repair
}

John W. Easton

National Center for Space Exploration Research, Glenn Research Center, Cleveland, Ohio

Peter M. Struk

Glenn Research Center, Cleveland, Ohio 


\section{NASA STI Program . . . in Profile}

Since its founding, NASA has been dedicated to the advancement of aeronautics and space science. The NASA Scientific and Technical Information (STI) program plays a key part in helping NASA maintain this important role.

The NASA STI Program operates under the auspices of the Agency Chief Information Officer. It collects, organizes, provides for archiving, and disseminates NASA's STI. The NASA STI program provides access to the NASA Aeronautics and Space Database and its public interface, the NASA Technical Reports Server, thus providing one of the largest collections of aeronautical and space science STI in the world. Results are published in both non-NASA channels and by NASA in the NASA STI Report Series, which includes the following report types:

- TECHNICAL PUBLICATION. Reports of completed research or a major significant phase of research that present the results of NASA programs and include extensive data or theoretical analysis. Includes compilations of significant scientific and technical data and information deemed to be of continuing reference value. NASA counterpart of peer-reviewed formal professional papers but has less stringent limitations on manuscript length and extent of graphic presentations.

- TECHNICAL MEMORANDUM. Scientific and technical findings that are preliminary or of specialized interest, e.g., quick release reports, working papers, and bibliographies that contain minimal annotation. Does not contain extensive analysis.

- CONTRACTOR REPORT. Scientific and technical findings by NASA-sponsored contractors and grantees.
- CONFERENCE PUBLICATION. Collected papers from scientific and technical conferences, symposia, seminars, or other meetings sponsored or cosponsored by NASA.

- SPECIAL PUBLICATION. Scientific, technical, or historical information from NASA programs, projects, and missions, often concerned with subjects having substantial public interest.

- TECHNICAL TRANSLATION. Englishlanguage translations of foreign scientific and technical material pertinent to NASA's mission.

Specialized services also include creating custom thesauri, building customized databases, organizing and publishing research results.

For more information about the NASA STI program, see the following:

- Access the NASA STI program home page at http://www.sti.nasa.gov

- E-mail your question via the Internet to help@ sti.nasa.gov

- Fax your question to the NASA STI Help Desk at $443-757-5803$

- Telephone the NASA STI Help Desk at 443-757-5802

- Write to: NASA Center for AeroSpace Information (CASI) 7115 Standard Drive Hanover, MD 21076-1320 
NASA/TM-2010-216071

AIAA-2009-6798

\section{Current Space Station Experiments Investigating Component Level Electronics Repair}

John W. Easton

National Center for Space Exploration Research, Glenn Research Center, Cleveland, Ohio

Peter M. Struk

Glenn Research Center, Cleveland, Ohio

Prepared for the

Space 2009 Conference and Exhibit

sponsored by the American Institute of Aeronautics and Astronautics

Pasadena, California, September 14-17, 2009

National Aeronautics and

Space Administration

Glenn Research Center

Cleveland, Ohio 44135 


\section{Acknowledgments}

The authors would like to thank Astronauts Sunita Williams, Michael Fincke, and Sandra Magnus; team members Eric Anderson, Gary Gorecki, Gregory Funk, Amber Krauss, Richard Oeftering, and Duc Truong; Arthur Perry and Alyssa Mueller of the Station Detailed Test Objective Office at NASA Johnson Space Center; SDTO sponsor Kevin Watson of the Constellation Supportability, Affordability, and Operability office; SDTO sponsor Anthony Butina of the ISS Logistics and Maintenance Office; Ivy Apostolakopoulos and Blake McCracken from the Operational Support Office at NASA Johnson Space Center, and students Anthony Rotella (Case Western Reserve University, Cleveland, OH), Joseph Ferry (University of Missouri Science and Technology, Rolla, MO), and Robert Banks (Shaker Heights High School, Shaker Heights, OH). This effort was funded by the Supportability Project in NASA's Exploration Technology Development Program Office (NASA Langley Research Center) and the ISS Vehicle Office (NASA Johnson Space Center).

This report contains preliminary findings, subject to revision as analysis proceeds.

Trade names and trademarks are used in this report for identification only. Their usage does not constitute an official endorsement, either expressed or implied, by the National Aeronautics and Space Administration.

Level of Review: This material has been technically reviewed by technical management.

Available from

NASA Center for Aerospace Information 7115 Standard Drive

Hanover, MD 21076-1320
National Technical Information Service 5285 Port Royal Road Springfield, VA 22161 


\title{
Current Space Station Experiments Investigating Component Level Electronics Repair
}

\author{
John W. Easton \\ National Center for Space Exploration Research \\ Glenn Research Center \\ Cleveland, Ohio 44135 \\ Peter M. Struk \\ National Aeronautics and Space Administration \\ Glenn Research Center \\ Cleveland, Ohio 44135
}

\begin{abstract}
The Soldering in a Reduced Gravity Experiment (SoRGE) and Component Repair Experiment (CRE)-1 are tests performed on the International Space Station to determine the techniques, tools, and training necessary to allow future crews to perform manual electronics repairs at the component level. SoRGE provides information on the formation and internal structure of through-hole solder joints, illustrating the challenges and implications of soldering in reduced gravity. SoRGE showed a significant increase in internal void defects for joints formed in low gravity compared to normal gravity. Methods for mitigating these void defects were evaluated using a modified soldering process. CRE- 1 demonstrated the removal, cleaning, and replacement of electronics components by manual means on functional circuit boards. The majority of components successful passed a post-repair functional test demonstrating the feasibility of component-level repair within the confines of a spacecraft. Together, these tasks provide information to recommend material and tool improvements, training improvements, and future work to help enable electronics repairs in future space missions.
\end{abstract}

\section{Introduction}

Future long-duration human exploration missions will be challenged by constraints on mass and volume allocations available for spare parts. Addressing this challenge will be critical to the success of these missions. As a result, it is necessary to consider new approaches to spacecraft maintenance and repair that reduce the need for large replacement components. On the International Space Station the maintenance concept for avionics focuses on the removal and replacement of entire Orbital Replacement Units (ORUs), with limited removal and replacement of circuit cards when possible. The next step to reducing the size of the items being replaced would be to implement component-level repair. This mode of repair has been implemented by the U.S. Navy in an operational environment and is now part of their standard approach for maintenance. It is appropriate to consider whether this approach can be adapted for application on future space considerations for spaceflight operations. The Component Level Electronic Assembly Repair (CLEAR) team at NASA Glenn Research Center, Cleveland, Ohio, has begun to explore the logistics, training, and research and development required to provide this capability to future International Space Station (ISS) operations as well as missions to the moon and Mars. Providing a repair capability can help relieve the costs of launching and storing full-sized spares rather than components and tools, and the ability to perform repairs adds to the flexibility and range of activities available to the crew (Refs. 1 to 5).

To this end, the CLEAR team proposed two Space Station Detailed Test Objectives (SDTOs). The first, Soldering in a Reduced Gravity Environment (SoRGE), examined the formation of solder joints during a mission, including the physical characteristics of the joint and void-defect mitigation techniques as well as examining the training and tools necessary to perform this soldering work. This is an expansion 
of previous work studying the effects of soldering in reduced gravity. This earlier work found that the amount of internal voids in a solder joint increased if the joint was manufactured in reduced gravity, compared to those generated in normal gravity. A technique to mitigate this effect was developed, and is tested in the lower gravity condition of the ISS in this work (Refs. 6 to 10). The second SDTO, Component Repair Experiment (CRE)-1, focused on the removal and replacement of circuit components, such as resistors and chips, on a functional circuit board in the reduced gravity environment of a space vehicle. CRE-1 focused on learning the current capability and the required improvements for training and equipping crew members to perform electronic repairs during a mission.

Both SoRGE and CRE-1 have been conducted aboard the International Space Station (ISS). The crew performed SoRGE operations during Expeditions 14 and 15, in March and May 2007, while the CRE-1 operations were conducted during Expedition 18, in February and March 2009. This paper presents the details of these experiments, including the materials used and training and tools provided, the results from inspecting the returned materials, and discusses these results and the lessons learned from the experiment operation and results.

\section{Experiment Description and Analysis}

The following sections will describe both the SoRGE and CRE-1 experiments, detailing the provided materials and processes for performing the experiment, crew training, and other aspects of the experiment operations. Following this is a description of the analysis of the results, including a description of the inspection processes, and the analysis of the joint interior to measure void defects in the SoRGE solder joints.

\section{SoRGE Experiment}

The SoRGE flight experiment studies the formation of through-hole solder joints in reduced gravity. The SoRGE flight experiment examined three solder and flux combinations. All samples used an active (RA) type flux, with either the type of solder or the method of applying the flux changing. The first combination consists of a $60 \%$ tin, $40 \%$ lead solder wire with a core of rosin solder flux, with samples produced in both normal and reduced gravity. The second solder and flux combination was a eutectic tinlead solder instead of the $60 \%$ tin, $40 \%$ lead solder in the first combination, with a core of rosin flux. (Eutectic alloys are alloys where, for a specific ratio of constituents, the constituents completely melt at the same temperature. Noneutectic alloys have states where one constituent does not completely melt for a given temperature. This plastic state may contribute to the formation of voids or other flaws in the soldering process. For tin-lead alloys commonly used in electronics soldering, the eutectic ratio of constituents is $63 \%$ tin and $37 \%$ lead.) Only reduced gravity samples were generated in SoRGE; results from previous work (Ref. 6) provide normal gravity samples for comparison. The third combination used a solid $60 \%$ tin, $40 \%$ lead solder wire and an external liquid rosin flux supplied in a syringe, which was applied to the circuit board and component immediately before soldering. The crew provided both normal and reduced gravity samples of this solder and flux type. The SoRGE team provided four kits for each solder-flux combination type, for a total of twelve kits. Each kit contained a circuit board with sixteen standard resistors fixed to the board with a RTV adhesive and each resistor lead positioned within a through-hole on the circuit board, shown in Figure 1. This provides the astronaut-operator with thirty-two solder joints to form on each circuit board. The kit also contains 32 weighed solder wires of the appropriate type, one for each solder joint.

Once on orbit, the crew assigned to this task used the kits described with ISS materials to form solder joints. The astronaut assembled the Containment Area, a tent-like glovebox which mounts on the Multipurpose Work Area (MWA), a table that attaches to rack frames in the walls of the ISS. The Containment Area, seen in use during SoRGE activities in Figure 2, includes mounting hardware for cameras or other equipment, a vacuum line to remove debris and vapor, and a circuit board clamp. With this equipment in place, the U.S. Soldering Kit and board clamp were installed within the Containment Area. The U.S. Soldering Kit is a commercial soldering iron wand based on the Weller TC201 series with 

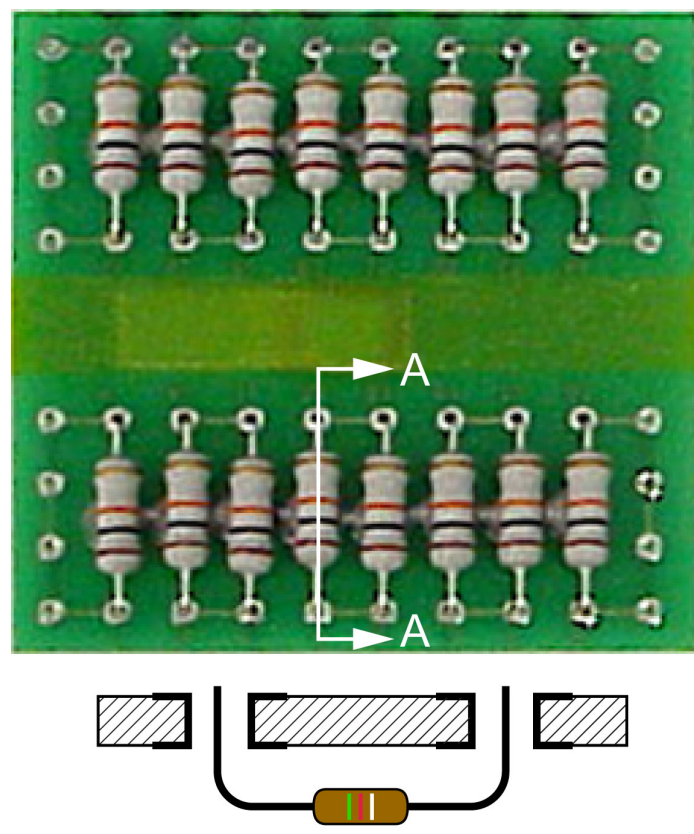

\section{Section A-A}

Figure 1.-An unused SoRGE circuit board and drawing of a resistor and two joint locations. The soldering occurs on the bare leg of the resistor, forming the soldered fillet. Solder flows into the through hole and forms the flowed fillet on the resistor body side of the circuit board.

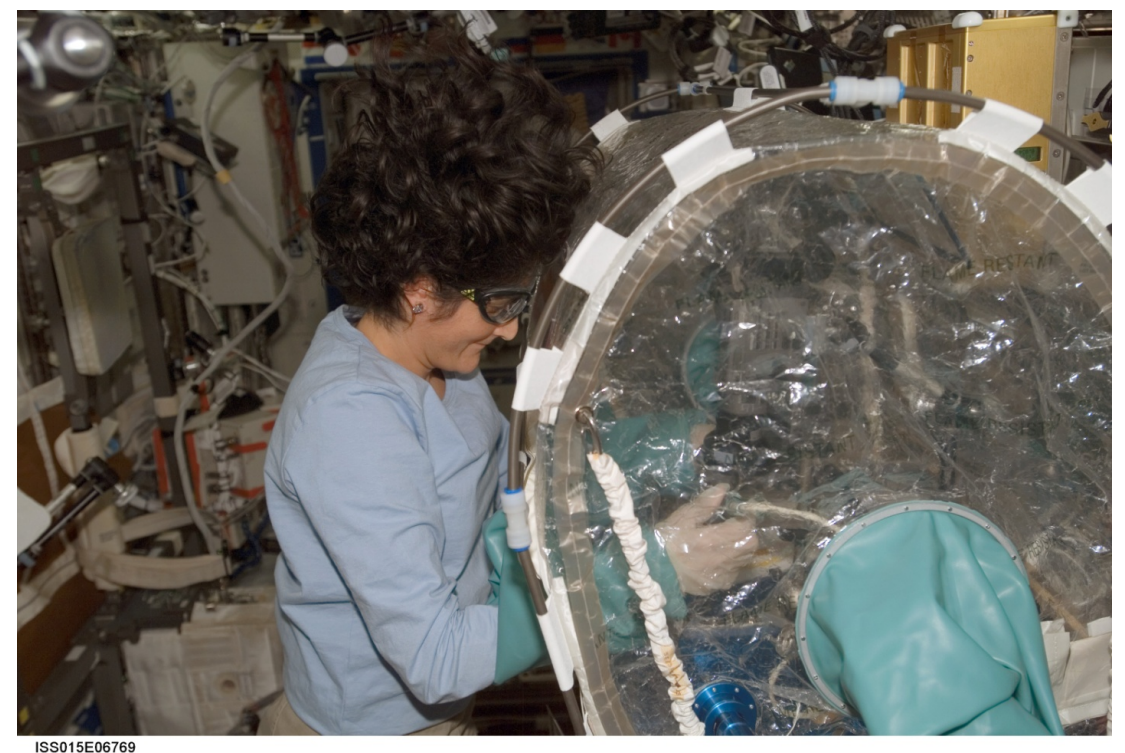

Figure 2.-Astronaut Sunita Williams works on SoRGE within the Containment Area aboard the ISS. 
a $600^{\circ} \mathrm{F}$ tip, modified to be powered by a cordless tool battery. Finally, the astronaut installed a camera and mounting arm within the Containment Area to record the soldering process. After assembling this equipment, the astronaut then removed one of the SoRGE kits from storage and placed the circuit board in the circuit board clamp, and arranged the solder wires and flux (if used) as comfortable. Prior to soldering, the astronaut closed the access port of the Containment Area, using glove ports to work with objects and viewing the work through the clear plastic side walls or a Fresnel lens mounted in the wall. Based on the previous work already described, the SoRGE experiment called for a specific process for forming a solder joint, described in the written experiment procedures and a training video developed by the team. In this process, the crew member applied the hot soldering iron tip to the joint area for a "mental count" of three seconds to preheat the area, then applied the appropriate solder wire to form the joint, removed the wire, and finished with a post-heating period of three seconds (again using a "mental count"), then removed the soldering iron. The astronaut applied the soldering iron and solder wire to the "soldered side" of the circuit board, as shown in Figure 1. In the analysis, this is fillet is referred to as the soldered fillet. The fillet which forms on the component side of the circuit board, from solder flowing through the through-hole, is referred to as the flowed fillet.

The SoRGE team did not have an opportunity to perform crew training prior to launch. The crew member did have familiarization with the various tool kits available on ISS, including the MWA, Containment Area, and U.S. Soldering Kit. The SoRGE team provided a set of written procedures as well as a training video illustrating the end to end soldering process and demonstrating the soldering techniques already described. The team did not have an opportunity to observe the crew activities in real time, but received video tapes of the activities with the returned circuit boards.

\section{CRE-1 Experiment}

In CRE-1, crew members remove and replace electronics components from functional, realistic circuit boards. These circuit boards have three separate, independently functional sections using different component mounting methods: plated through-hole, 0.050 in. or standard pitch surface mount, and 0.025 in. or fine pitch surface mount. When powered and activated by a switch on the circuit board, a LED in each section blinks if the circuit in that section is functional. The parts removed and replaced are a plated through-hole resistor (R1), an eight pin, through-hole Dual Inline Package (DIP) integrated circuit (U2), and an eight pin, standard pitch surface mount Small Outline Integrated Circuit (SOIC) (U4). Due to additional crew time, CRE-1 also included the removal of two fine pitch Thin Small Outline Package (TSOP) integrated circuits, one with eight pins (U6), and the other with sixteen pins (U7). Figure 3 shows these components on a CRE-1 circuit board. CRE-1 provided five circuit boards. Three boards had a conformal coating applied to the board. The conformal coating is a thin plastic coating applied to the circuit board after manufacturing to provide environmental and fire protection to the board, and must be locally removed during component removal and replacement processes. Two of the CRE-1 circuit boards were not coated, initially to provide practice for the crew or as a contingency if the crew encountered difficulty removing the conformal coating.

Removal and replacement of these components requires four general steps. First, crew members remove conformal coating material from the component joints. Next, they remove the component from the circuit board. For the resistor R1, the crew remove the part by melting the solder joint and pulling the legs, one at a time, through the through-hole. For the chips U2 and U4, the crew cut the legs to remove the chip. After removing the component, the next step is to clean the area of any remaining conformal coating, remove the original solder, and remove any remaining leg debris. For U2, leg debris was removed by heating the original solder joint and pulling the leg debris out of the joint with tweezers. The crew removed leg debris from U4 by one of two methods: heating the joint and wiping off the leg debris 


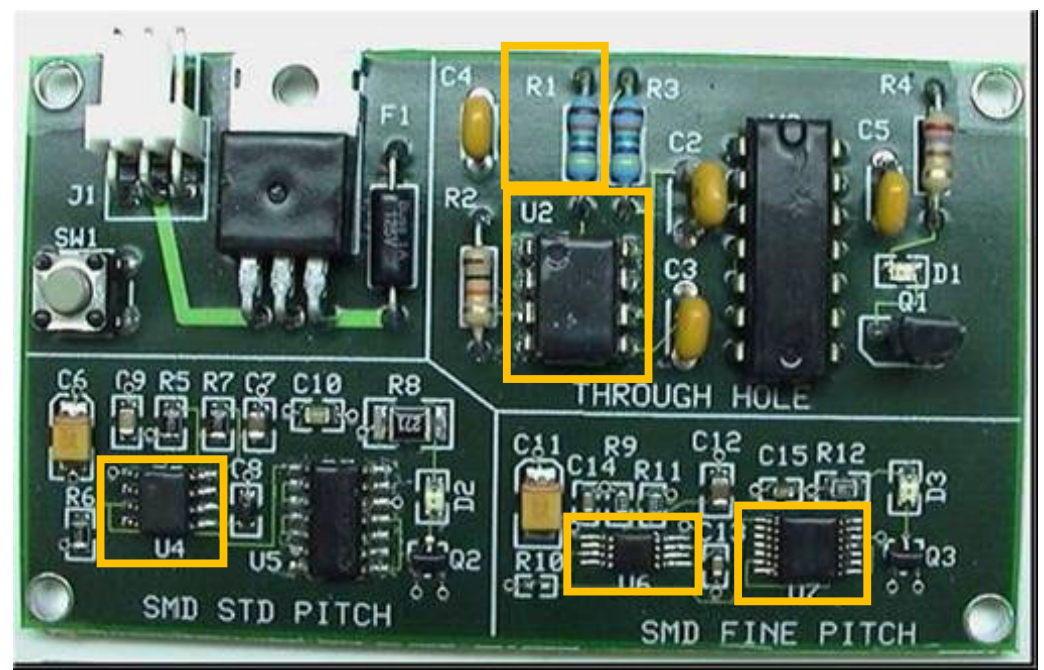

Figure 3.-The CRE-1 circuit board, with R1, U2, U4, U6, and U7 positions highlighted.
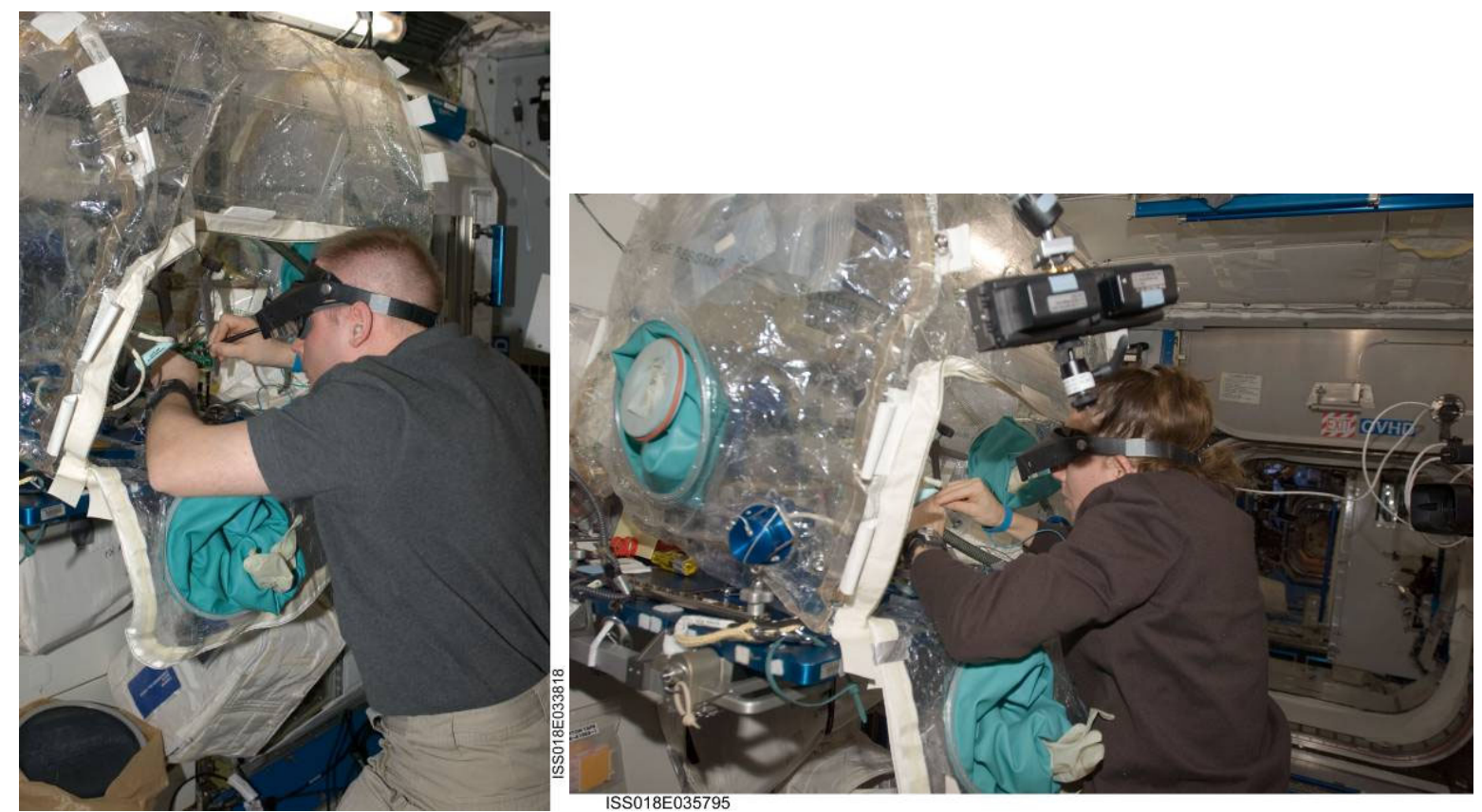

Figure 4.-Astronauts Michael Fincke (left) and Sandra Magnus (right) perform CRE-1 operations in the Containment Area aboard the ISS. 
and solder with solder wick, or heating the joint and removing the leg debris with tweezers. Replacement components R1 and U2 are inserted into the circuit board through-holes, and held in place by clinching the leads. For U4, one of the circuit board pads is loaded with a small amount of solder. The crew then holds and aligns the new component with tweezers, and reflows the new solder to tack that leg in place. Finally, all the leads of the new component are soldered in place for components R1, U2, and U4; because removal of U6 and U7 were additional, unplanned data points, no replacement parts were provided and processes for these components stopped with cleaning the area after removing the original component. At the end of their work, the crew places the circuit board and components in storage bags, which were returned to the CLEAR team for analysis.

Crew members used tools from a small tool kit provided by the CRE-1 team as well as tools and facilities already present on the ISS. The CRE-1 tool kit contains three small-jawed tweezers (curved, straight, and reverse), a fine-tip cutter for small components, a standard-tip cutter for larger (throughhole) components, a dental pick, a fiberglass stick for removing conformal coating, 1/32- and 1/8-in. soldering iron tips, a small spool of solder with a core of no-clean flux, a spool of solder wick for removing solder from the circuit boards, and a syringe of liquid flux to aid in soldering activities. The existing ISS facilities include the U.S. Soldering Kit, a battery powered soldering iron used for all the soldering tasks in CRE-1. The crew used the (MWA) and the Containment Area as with SoRGE, though with the Containment Area front panel open during work periods rather than using the glove ports during operations, as was done in SoRGE. The crew also used a vacuum to remove and dispose of debris generated during the repair tasks. The crew also had access to a magnifying visor, which was not available during SoRGE operations. Figure 4 shows the setup used on the ISS during CRE-1 operations. The crew used a visor magnifier to aid in seeing the small components and legs under work. The crew also used a still camera to take photos of the circuit board, initially as a record of the work but in later sessions as a magnification aid to the crew during work in addition to providing a record of the work.

The team had an opportunity to perform crew training prior to launch. This training consisted of hands-on conformal coating removal, removing components R1, U2, and U4, removing legs and original solder for U2 and U4, and installing new U2 and U4 components. The crew also had access to written procedures and a training video showing the end to end process of removing and replacing each of R1, $\mathrm{U} 2$, and U4. The CRE-1 team had the opportunity to view the crew progress real-time via video downlink, and was able to briefly answer crew questions and provide a small amount of feedback at the end of each work session.

\section{Circuit Board Inspections for SoRGE and CRE-1}

For both SoRGE and CRE-1, a visual inspection was performed by a NASA trained, flight qualified electronics technician using a stereo microscope, with magnifications varying from $7 \mathrm{X}$ for general inspection to 20X for close inspection of specific joint features, to inspect for a variety of surface flaws in the solder joint, described in NASA standard 8739.3 (Ref. 11). The inspection included analysis of the flowed fillet, the soldered fillet, and the overall acceptance of the solder joint. Each fillet passed, marginally passed, or failed inspection. Joints that marginally passed had some problem with the soldering process that would have lead to a failing evaluation for an experienced technician, but may be allowed given the astronaut's experience level and minimum impact to the circuit. If both fillets of a joint passed the inspection, then the entire joint passed. The inspection report included notes on why the joint did not pass inspection, but no notes when the joint passed. Marginally acceptable solder joint sides also had notes on the potential problem with the solder joint.

The inspection of the CRE-1 circuit boards follows an inspection of the still photos taken by the crew and the down linked video of ISS operations by the electronics technician. Inspecting the circuit boards followed the same process as the inspection of SoRGE solder joints, additionally noting cases where the work may be functional, but not passing the NASA standard. The technician also performed a functional test of the CRE-1 circuit boards, noting the peak current draw in addition to the rate the LEDs on the circuit board blinked. 
For the measurement of internal voids, the team first selects joints from each solder and flux combination for removal from the original circuit board. The team uses the results of the visual inspection process selecting joints that pass the inspection for the flux cored solder cases. The tests with an external liquid flux required expanding this criteria to include joints with a passing flowed fillet (but not soldered fillet), eventually leading to seven to ten joints per solder and flux combination and gravity level for analysis. These joints are encased in a plastic metallographic mount for both protection and future metallographic analysis. The joints are sent to a commercial nondestructive testing laboratory, YXLON International in Akron, Ohio. This laboratory performed CT scanning of the individual solder joints in a process similar to previous work (Ref. 6), producing between 150 and 200 images for each solder joint with a resolution ranging from 0.015 to $0.020 \mathrm{~mm}$, each image taken along the center axis (parallel to the component lead) of the solder joint. Figure 5 shows a sequence of images from one of these joints, with the spacing between each image $0.018 \mathrm{~mm}$. Images $\mathrm{a}$ and $\mathrm{b}$ show the increasing diameter of the soldered fillet, while images $\mathrm{i}$ and $\mathrm{j}$ show the decreasing diameter of the flowed fillet. The remaining images are from the interior through-hole region. These images show the solder as a bright white, with a gray lead and gray-to-black internal voids.

With the sequence of images describing the internal structure of the solder joints, the SoRGE team used ImageJ (Ref. 12) to measure the fraction of voids within the solder joint, and compare these values for the various flux combinations in both reduced and normal gravity. The process for measuring void areas and volumes requires two steps. First, the total area of the solder joint in each image is measured, using a grayscale threshold to isolate the joint area from external features in the image, such as $\mathrm{x}$-ray reflections or plating. This process counts the area (or pixels) highlighted by the thresholding process, and includes any interior holes not highlighted by thresholding. The next step in the void measurement process is to measure the area (or pixels) of solder, isolating and removing the voids. The process uses algorithms to increase the contrast and sharpen the image before performing a threshold operation, isolating the solder area. After this operation, the routine then counts the highlighted pixels representing solder in the joint area. After making these two measurements, total joint area and solder area, the user must then measure the area of the component lead; this is done manually. Once this is done, the void area may be calculated. First, the average lead area and solder area are subtracted from the total area measurement for each image. The remaining value is the area of voids in the image. Integrating the total joint area (minus lead area) as well as the void area over the joint gives the total volume and void volume. The integrations were calculated using the trapezoidal rule (Ref. 13). The ratio of the void volume to total volume, the void volume fraction, gives a measure of the total amount of voiding in a particular joint, and is used to compare joints across solder and flux type and between gravity levels. The analysis also examines three separate regions of each joint, as shown in Figure 6. These regions are the soldered fillet, where the crew member heated the joint and added solder, the annular region within the circuit board through-hole, and the flowed fillet on the opposite side of the circuit board, near the resistor. Breaking the joint into these regions allows for some analysis of the void distribution within the joint.

\section{Results}

\section{SoRGE Inspection and Operational Results}

The video record of SoRGE operations provided information on the tools and operating environment of the ISS, as well as the effectiveness of the training video provided by the SoRGE team. In general, the circuit board fills the camera field of view, providing a close enough view to see the soldering techniques used, as well as any difficulties encountered during soldering. This view generally did not have enough

magnification to evaluate the solder joints. 

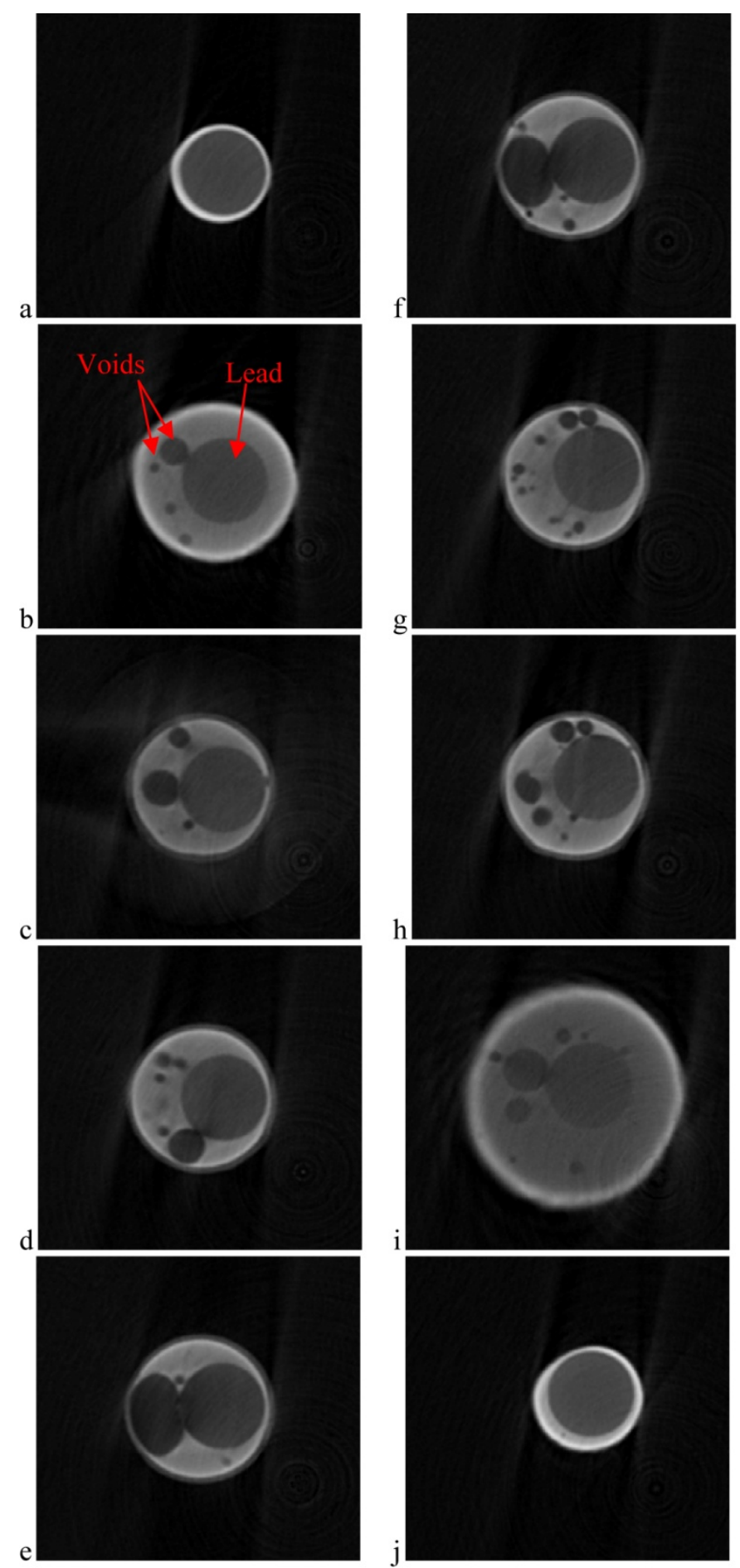

Figure 5.-Sequence of images describing the interior of a solder joint. The images show the lead and voids within the equally spaced images. Images $a$ and $b$ are taken from the soldered fillet, images $\mathrm{c}$ through $\mathrm{h}$ from the annular region, and images I and $\mathrm{j}$ from the flowed fillet. Image $\mathrm{b}$ demonstrates the lead and typical voids. 

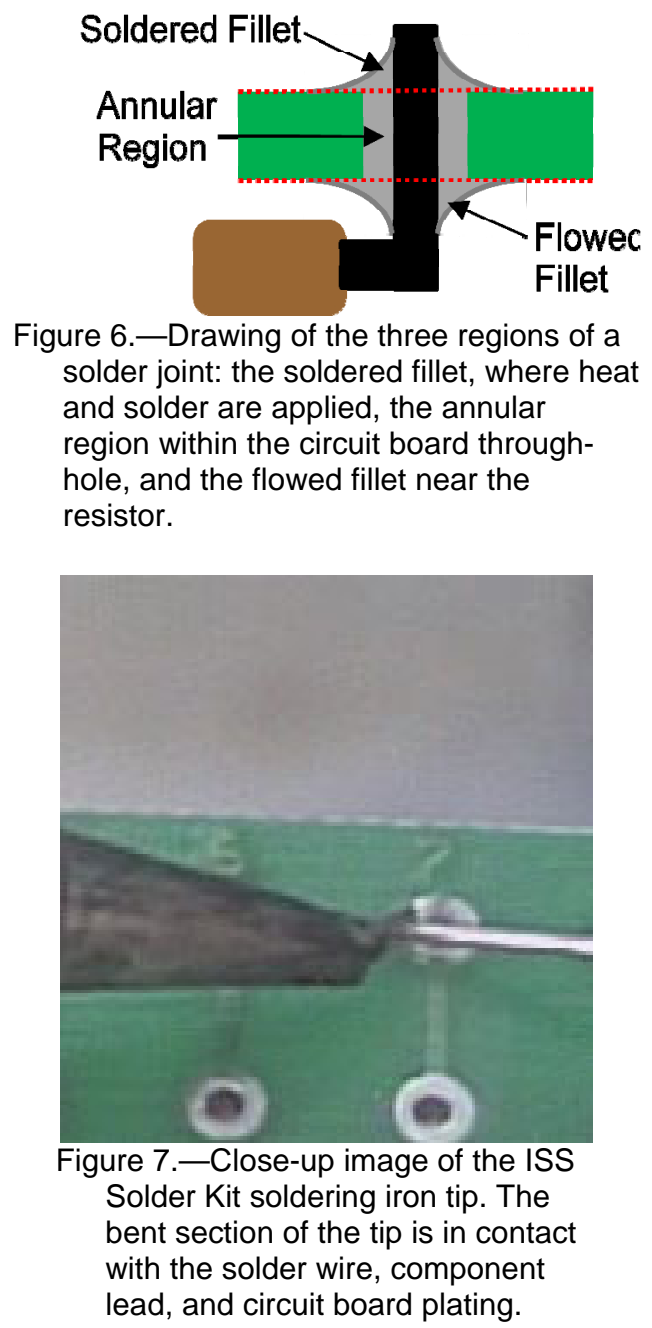

The video record showed a problem with the ISS Soldering Iron Kit tip that was not expected by the SoRGE team, and may have negatively impacted the performance of the operator. As seen in Figure 7, the soldering iron tip used was curved, with a bend at the approximate middle of the tip. The ISS Soldering Iron Kit does not include any soldering iron tips with a bend; all provided tips are straight. This indicates that the soldering iron tip was damaged prior to use on the SoRGE experiment. The damaged soldering iron tip has a number of implications in terms of effectiveness for both the SoRGE experiment and general use during other ISS operations. First, the bend could indicate a change in tip temperature. The soldering iron tip is resistively heated, and the action that caused the tip to bend may have damaged the electrical connection between the tip and the soldering iron, connections between layers of material in the tip, electrical connections within the tip, or any combination of these effects. The change in tip shape could also affect the contact between the soldering iron tip and the circuit components - the resistor leg and circuit board through-hole or land - in a way that reduces the rate of heat transfer from the soldering iron tip to the joint area. While the tip used did provide enough heat to melt the solder wire and form solder joints, the potential reduction in performance of the tip may have made the astronaut's task more difficult than expected, and adversely affect the results of the experiment.

Analysis of the videotaped operations also pointed out a problem with the video training that the SoRGE team provided. The training video did not adequately emphasize proper soldering technique for someone who never soldered previously. This video focused on an end-to-end process for forming solder 
joints, including applying an external liquid flux if necessary, the time required to preheat the joint prior to adding solder, and the post-heat time which occurs after adding solder to the joint but prior to removing the soldering iron. More emphasis in training is needed on the proper soldering technique (e.g. making a heat bridge and positioning the soldering iron). As a result, only a limited number of solder joints passes the post-flight visual inspection as discussed below. Nonetheless, the SoRGE team feels that the training video format can be effective provided that we emphasize certain key techniques of the soldering process.

The data in Tables 1 through 3 are the results of a visual inspection of the SoRGE flight boards worked aboard the ISS. The inspection criteria are based on the NASA standard, and the tables show the number of soldered fillets, flowed fillets, and total joints that passed this inspection criterion. For some joints, either the soldered fillet or flowed fillet passed the inspection, while the other failed; only joints where both the soldered and flowed fillets passed are counted in the "Both Fillets" row. As the data show, all solder and flux combinations presented challenges for the crew to form solder joints that pass the NASA standard. The crew member was more successful soldering with the flux cored solders than with the solid solder wire and external liquid flux, and somewhat more successful with the eutectic flux cored solder than with the $60 \%$ tin- $40 \%$ lead flux cored solder. Difficulties with wetting the solder joint were one of the most common problems with the soldering process. In a number of cases, the operator added solder to the bottom of the board, sometimes in large or excessive amounts, but the solder did not flow, or flowed poorly, through the circuit card through-hole and did not wet the component leg and circuit board pad on the top side of the circuit board. The poor wetting occurred with both flux cored solder wire and solid solder wire with an external, liquid flux. This problem can be caused by insufficient heating of the solder joint, whether through technique (such as not forming a heat bridge prior to adding solder for the joint, or through improper placement of the soldering iron tip in the solder joint area) or through damage to the soldering iron tip not allowing the tip to reach full operating temperature. Other problems, typically seen on the soldered fillet, include solder spikes and solder drag. In both cases, molten solder does not immediately detach from the soldering iron as the iron is removed from the joint. The solder does not release from the soldering iron tip for several potential reasons including overheating of the joint, the operator not removing the tip fast enough, or the flux in the joint area deactivating due to time or overheating. In other cases, the operator did not add enough solder to form a solder joint, or added the solder to the end of the component lead, not at the lead-circuit board land interface. These joints failed simply because there was not enough solder to form the joint. A final problem found during inspection was voids (sometimes referred to as "blowholes") seen in the surface of the solder joint. Trapped gases within the solder joint escaped just before the solder solidified, leaving a dimple in the surface of the solder joint. This is usually indicative of voids remaining within the solder joint, and leads to rejection during the visual inspection.

TABLE 1.-VISUAL INSPECTION RESULTS FOR SOLDER JOINTS FORMED IN REDUCED GRAVITY USING 60\% TIN-40\% LEAD FLUX CORED SOLDER.

\begin{tabular}{|l|c|c|}
\hline \multicolumn{1}{|c|}{ Location } & Number passed & Percentage passed \\
\hline Soldered fillet & 23 & 36 \\
\hline Flowed fillet & 34 & 53 \\
\hline Both fillets & 13 & 20 \\
\hline
\end{tabular}

TABLE 2.-VISUAL INSPECTION RESULTS FOR SOLDER JOINTS FORMED IN REDUCED GRAVITY USING EUTECTIC FLUX CORED SOLDER.

\begin{tabular}{|l|c|c|}
\hline \multicolumn{1}{|c|}{ Location } & Number passed & Percentage passed \\
\hline Soldered fillet & 29 & 45 \\
\hline Flowed fillet & 30 & 47 \\
\hline Both fillets & 20 & 31 \\
\hline
\end{tabular}


TABLE 3.-VISUAL INSPECTION RESULTS FOR SOLDER JOINTS

FORMED IN REDUCED GRAVITY USING 60\% TIN-40\% LEAD

SOLID SOLDER WIRE WITH EXTERNAL LIQUID FLUX

\begin{tabular}{|l|c|c|}
\hline \multicolumn{1}{|c|}{ Location } & Number passed & Percentage passed \\
\hline Soldered fillet & 23 & 36 \\
\hline Flowed fillet & 4 & 6 \\
\hline Both fillets & 3 & 5 \\
\hline
\end{tabular}

There are two main reasons for the difficulties found in producing solder joints that meet the NASA standard. First, the astronaut did not receive training prior to the mission, and did not have any previous experience to use as a reference. While the astronaut stated, and the video record shows, that the written procedures and training video were helpful, some additional training and experience prior to launch would have provided a better foundation for performing the soldering work. The astronaut also commented that visibility and magnification were problems. Seeing through the walls of the Containment Area was difficult because the walls had been collapsed and packed many times, producing creases and wrinkles; the interior was only visible through the Fresnel lens. Also, the working distance between the circuit board and the crew member's eyes was large, making working and seeing the joints difficult. The visibility problem was alleviated by using the view finder in the video camera as a vision aid, but this is only a temporary solution. Second, it was more difficult to form solder joints using the external liquid flux than to form joints with either of the solders with a flux core. Use of liquid flux is more difficult because once activated, by heating the joint area with the soldering iron, the flux will lose effectiveness with additional time and heat, making the application of solder critical. Another difficulty is the liquid flux may not wet all the areas where solder must wet and flow to form a joint, such as into or through a through-hole or onto the plating on the flowed fillet side of the circuit board. Flux cored solder wires do not experience this problem, because the flux is mixed with the liquid solder and flows with the solder, preparing the surface as it flows.

\section{SoRGE Void Fraction Results}

The analysis of images produced by CT x-ray scan described earlier provide information on the amount of voids present in the solder joints and some information on the distribution of these voids. Table 4 presents these results. The data presented are the average and the range of void volume fractions in each region of the solder joint (soldered fillet, annular region, and flowed fillet) as well as for the overall joint. As the data in the table show, the range of void volume fraction can be quite large. The reduced gravity averages include data from seven to ten joints, while the normal gravity results are the average of data from five joints. The data are presented for all three types of solder and flux, as well as both reduced and normal gravity for the joints formed using $60 \%$ tin- $40 \%$ lead solder. No normal gravity data with eutectic solder is presented, as such samples could not be produced due to time constraints with the crew member. For this reason, the reduced gravity results from eutectic-solder joints in this work are compared with previous normal gravity results (Ref. 6), where the overall void fraction was less than $1 \%$ for each of two samples.

One result from these tests is that the type of solder and flux used affects the amount of voids found with the solder joint. In both normal and reduced gravity, joints formed with flux cored $60 \%$ tin- $40 \%$ lead solder wire had more internal voids over the entire solder joint than the other solder and flux types. Joints formed using a eutectic, flux cored solder wire had fewer voids overall, and samples generated with an external liquid flux had fewer voids than the other solder and flux types. This is consistent with previous work (Refs. 1 to 5), where joints formed with an external liquid flux also had fewer internal voids than other cases in reduced gravity aircraft tests. 
TABLE 4.-AVERAGE VOID VOLUME FRACTION FOR VARIOUS SOLDER AND FLUX

COMBINATIONS, IN NORMAL AND REDUCED GRAVITY, FORMED DURING SORGE.

\begin{tabular}{|l|c|c|c|c|c|c|c|c|}
\hline \multirow{2}{*}{ Solder and flux type } & \multicolumn{2}{|c|}{$\begin{array}{c}\text { Soldered fillet void } \\
\text { volume fraction } \\
\text { (\%) }\end{array}$} & \multicolumn{2}{|c|}{$\begin{array}{c}\text { Annular void volume } \\
\text { fraction } \\
\text { (\%) }\end{array}$} & \multicolumn{2}{|c|}{$\begin{array}{c}\text { Flowed fillet void } \\
\text { volume fraction } \\
\text { (\%) }\end{array}$} & \multicolumn{2}{|c|}{$\begin{array}{c}\text { Joint overall void } \\
\text { volume fraction } \\
\text { (\%) }\end{array}$} \\
\cline { 2 - 9 } & Average & Range & Average & Range & Average & Range & Average & Range \\
\hline $\begin{array}{l}\text { 60\% tin-40\% lead flux } \\
\text { cored, 0g }\end{array}$ & 4.1 & $1.3-15.1$ & 23.3 & $8.8-45.2$ & 6.7 & $1.8-16.1$ & 11.8 & $4.4-23.8$ \\
\hline $\begin{array}{l}\text { 60\% Tin-40\% lead flux } \\
\text { cored, 1g }\end{array}$ & 7.2 & $1.8-15.3$ & 10.4 & $5.0-18.4$ & 4.5 & $0.7-13.4$ & 7.8 & $3.3-11.4$ \\
\hline $\begin{array}{l}\text { Eutectic flux cored, } \\
\text { og }\end{array}$ & 3.8 & $0.8-9.5$ & 15.3 & $7.4-28.9$ & 7.9 & $1.3-19.7$ & 9.7 & $4.3-17.1$ \\
\hline $\begin{array}{l}\text { 60\% tin-40\% lead, } \\
\text { external liquid flux, 0g }\end{array}$ & 4.3 & $0.9-12.1$ & 13.6 & $3.2-26.5$ & 4.9 & $1.0-12.4$ & 6.9 & $1.7-11.3$ \\
\hline
\end{tabular}

The data also show a change in the distribution of internal voids, depending on the gravity level of the work environment. For both cases using the $60 \%$ tin- $40 \%$ lead solder, the annular region of the joint had a higher void volume fraction than either fillet in both normal and reduced gravity. The relative difference in void volume fraction between the annular region and the soldered fillet region changes between reduced and normal gravity. In reduced gravity, the annular region has a significantly larger void volume fraction than the soldered fillet, but in normal gravity the difference in void volume fraction is much smaller. This may indicate the effect of buoyancy in the distribution of voids. When soldered in normal gravity, buoyant forces will drive any gas bubbles within the still liquid solder joint upward toward the soldered fillet, resulting in a proportionally larger void volume fraction in this region when compared to the rest of the joint. In reduced gravity, the buoyant force is almost negligible, and voids would generally remain trapped in the annular region of the joint. Buoyant forces may also explain why joints formed in normal gravity have a smaller void volume fraction than joints formed in reduced gravity. The buoyant forces drive gases out of the joint while the solder is liquid, while in reduced gravity the gasses remain trapped within the joint.

\section{CRE-1 Inspection and Operational Results}

The video record of the CRE-1 operations generally showed good progress in the removal and replacement of the circuit components. The crew generally used the techniques demonstrated in the crew training exercise and in the training video. The crew did comment at a later time that the training video was more helpful than the written procedures, with good visual descriptions of the processes and more accessible during work. The crew were seen (and commented on) viewing a section of the training video immediately before attempting the specific task, which was difficult to do with written procedures. The crew did experience some problems cleaning the leg debris after removing component U4, though this is attributable to inexperience; later attempts at this task were successful. The crew also experienced problems removing components U6 and U7 as these components were not part of the original plan, and the crew did not have training or appropriate tools. An additional problem was the lack of appropriate magnification for components with leads as small as those found on U6 and U7.

The crew also developed specific techniques for removing components U6 and U7, then cleaning the circuit board pads of leg and solder debris. The crew attempted to cut all the legs with fine cutters; this worked well in one instance, but caused damage to the circuit board pad in a second attempt. The crew also attempted to melt and bend each leg of the component up off the circuit board. Once again, this worked well for one component, but caused damage to the circuit board in another. To remove the original solder and leg debris, the crew attempted, for different components, both heating the joint and picking the leg debris out with tweezers and heating and wiping the leg and solder debris into solder wick. Both techniques worked well. As said, work on these components was unplanned and improvised, based on previous work (particularly with U4) and the tools at hand. This work pointed to a need for greater 
magnification (visibility of the small component legs was an issue) and the need for appropriate tools, but also demonstrates the flexibility of the crew to adapt and work on unfamiliar tasks, points in favor of providing the crew with the appropriate tools and facilities to practice electronics repair during a mission.

Tables 5 and 6 summarize the results of the visual and functional test of the ISS circuit boards. Each table lists the components worked on each board, and if the component is functional, passes inspection based on NASA Standard 8739.3 (Ref. 11), and further rework is necessary. Components are judged to be functional if the LED for that section of the circuit blinked in the correct pattern, or if the visual examination did not show any flaws preventing operation. Examining components to the NASA Standard indicates that the work is of the same quality that technicians and engineers must meet for flight hardware, and is judged based on the geometry and surface finish of the new solder joints. The rework comment indicates if the further work is required to provide a higher quality joint, though not necessarily meeting the NASA standard in final form. In some cases, reworking a solder joint to meet the NASA standard is not worth the risk of damaging a component or part of the circuit board during rework. For example, component R1 on Board 03 failed the visual inspection due to excessive solder on the bottom of the solder joint. This failure of the visual inspection, however, does not lead to functional failure, and no further work is needed.

TABLE 5.-INSPECTION RESULTS FROM CONFORMAL COATED CRE-1 CIRCUIT BOARDS

\begin{tabular}{|c|c|c|c|c|c|c|c|c|c|c|c|}
\hline & \multicolumn{3}{|c|}{ Board 01 } & \multicolumn{4}{|c|}{ Board 02 } & \multicolumn{3}{c|}{ Board 03 } \\
\cline { 2 - 15 } & R1 & U2 & U4 & R1 & U2 & U4 & U6 & U7 & R1 & U2 & U4 \\
\hline Functional? & Yes & Yes & Yes & Yes & Yes & Yes & Yes & No & Yes & Yes & No \\
\hline Pass 8739.3? & Yes & No & No & Yes & Yes & No & N/A & N/A & No & No & No \\
\hline Rework? & No & Yes & No & No & No & No & No & Yes & No & Yes & Yes \\
\hline
\end{tabular}

TABLE 6.-INSPECTION RESULTS FROM UNCOATED CRE-1 CIRCUIT BOARDS

\begin{tabular}{|c|c|c|c|c|c|c|c|c|}
\hline & \multicolumn{4}{|c|}{ Board 09 } & \multicolumn{3}{c|}{ Board 10 } \\
\cline { 2 - 9 } & R1 & U2 & U4 & U6 & U7 & R1 & U2 & U4 \\
\hline Functional? & Yes & Yes & No & No & No & Yes & Yes & No \\
\hline Pass 8739.3? & No & No & No & N/A & N/A & No & No & No \\
\hline Rework? & No & Yes & Yes & Yes & Yes & No & Yes & Yes \\
\hline
\end{tabular}

Figures 8 through 10 show some of the soldering issues found in the initial inspection. Figure 8 shows both a good solder joint, and a solder joint that failed inspection and would require rework. The good solder joint shows a fillet on the top side of the circuit board, wetting the leg of the component. The second solder joint does not have sufficient solder filling the plated through-hole; in practice, this solder joint would require rework to ensure proper wetting of the solder and a functional circuit, but is functional as-is.

Figures 9 and 10 show an issue found in working with $U 4$, a surface mount device. In many cases, the new component is not flat on the circuit board. This requires solder to flow between the bottom of the chip leg and the circuit board pad, which does occur in the case shown in Figure 9. In other cases, such as that shown in Figure 10, the solder does not wet both the raised chip leg and the circuit board pad, leading to an open circuit and faulty installation. This would require a repeat attempt to complete the repair, which the crew were instructed not to do as part of the experiment design. 


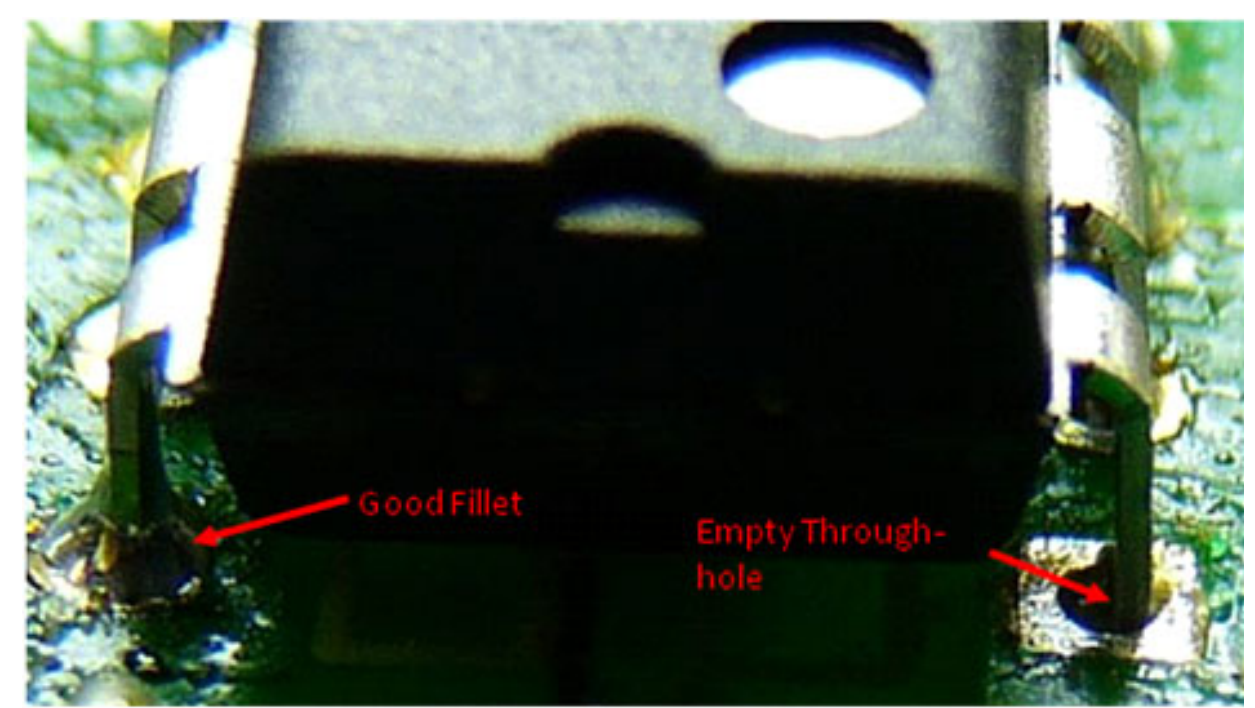

Figure 8.-A replacement U2 component on a CRE-1 circuit board. The image shows a joint which passes the NASA standard as well as one joint that does not pass because the board through-hole is not filled with solder, but is functional.

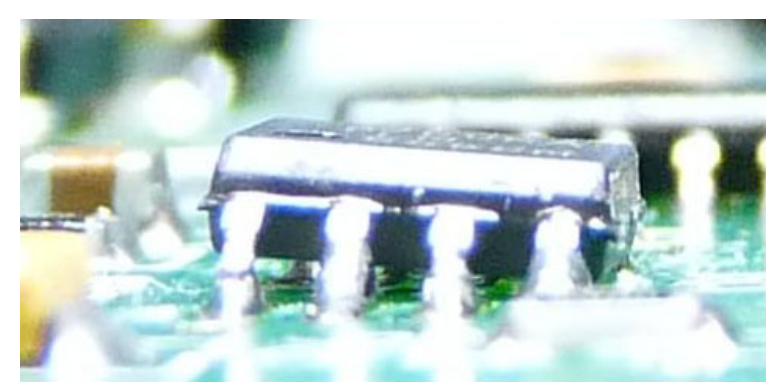

Figure 9.-A replacement U4 on a CRE-1 circuit board. This image shows the component not resting flat on the board surface. The joints do not pass NASA standard, but are functional.

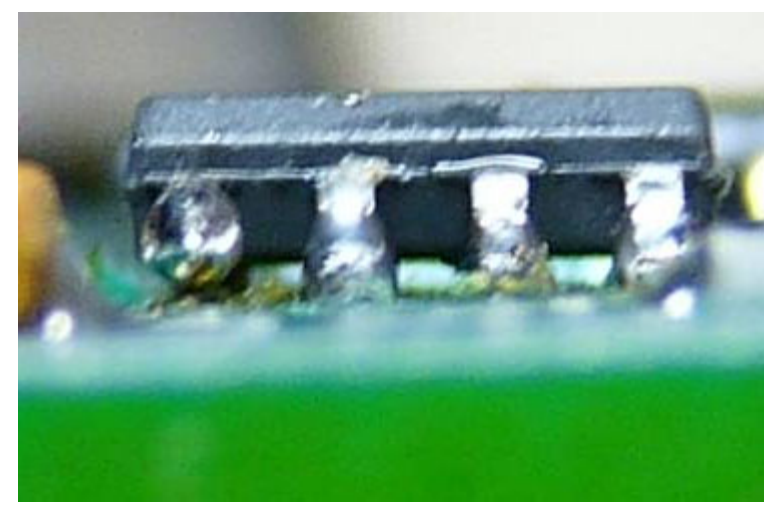

Figure 10.-A replacement U4 on a CRE-1 circuit board. In this case, the first leg is not soldered to the circuit board, requiring rework. 


\section{Discussion}

A key finding of the SoRGE and CRE-1 SDTOs is that crews are capable of performing soldering and electronics repair operations in the reduced gravity, closed environment of a space vehicle or habitat. As the data in Tables 1 through 3 shows, the astronaut was able to form solder joints that pass NASA standards with all the solder and flux types, though all the solder operations generated fewer passing joints than expected. Further, the results of Tables 5 and 6 show that the crew is able to perform the tasks necessary to remove and replace electronic components from a circuit card, and return that circuit to a functional condition. The results of these SDTOs also show some of the needed improvements to make electronics repairs an effective option during a mission for crew members and mission planners.

The first recommendation focuses on the selection of solder wire to use for electronics repairs. As the SoRGE results show, the best solder and flux combination to use, strictly in terms of void mitigation, is a solid wire with an external liquid flux. However, the results also show that this solder and flux combination was the most difficult to work with, yielding the smallest number of effective solder joints. The eutectic solder, with a flux core within the solder wire, is a better choice for general soldering tasks and repairs. It provides better void mitigation properties than the $60 \%$ tin- $40 \%$ lead flux cored solder wire, and is easier to use than the solid solder wire with external liquid flux. The use of the solid solder wire with liquid flux should be reserved for cases where internal void generation must be kept to a minimum. Additionally, NASA must evaluate when and where void mitigation considerations dictate using special methods and techniques, such as using a solid solder wire with external liquid flux. In industry the amount of acceptable voiding depends on the function and criticality of the overall product, and each manufacturer must decide this on their own, with very few "rules of thumb" to guide the decision. Determining such conditions are beyond the scope of SoRGE and CRE-1.

A second area for improvement is in the training of crew members for electronics repairs. The crew members performing both the SoRGE and CRE-1 work recommended the use of training videos for future work. Training videos should emphasize the techniques required and provide examples of both good techniques and outcomes as well as flaws and actions to avoid. These videos could be used both for general soldering instruction and refresher as well as new videos for specific repairs transmitted to the crew from ground support teams. The crew should also have access to practice boards and components during a mission. This provides a capability for refresher training and maintaining competence, as well as practicing a repair prior to performing it. The crew training should begin well before the mission, with hands on instruction for all crew members. One of the crew members should also have electronics repair experience, either professional experience or as a personal hobby, participate in the mission.

NASA should also improve the tools and facilities provided to the crew for electronics repair work. One area for improvement is the U.S. Soldering Kit. A new soldering iron should be improved to provide a hotter iron tip (at least $700{ }^{\circ} \mathrm{F}$ ) with better temperature control. The hotter soldering iron tip will allow for operations with multilayer circuit boards which could not be done in the CRE-1 work and are more common in industry and in flight avionics. The higher temperature tips are more common in general use, and for this reason more shapes and sizes of the higher temperature tips are available, expanding the types of components that may be worked as well as making work currently possible easier to perform and more reliable. In addition to the soldering iron, other hand tools should be included. CRE-1 provided a number of small hand tools for use with the experiment, and they remain in the ISS tool kit for future use by the crew. The number and types of tools provided should be expanded, providing tools for manipulating smaller components or performing other tasks such as forming and inserting component legs in a circuit board to repairing damaged circuit traces and lands on a circuit board.

NASA should also add tools and improve existing tools and facilities to provide better visibility and magnification of the work area. The crew performing both SoRGE and CRE-1 commented that seeing the work was a challenge. The crew should have access to improved magnification. This can include higher magnification visors than those already provided, or viewing the work through a live camera and monitor. Microscopes providing up to 45X magnification to the naked eye (and up to 100X with video camera attachments) provide detailed viewing of the smallest electronics components. Additionally, 
improvements to the Containment Area will help the crew perform electronics repairs. For SoRGE, the Containment Area proved to be too large, with a large distance between the circuit board and the crew member's eyes. Making a smaller Containment Area can alleviate this problem and make the area more ergonomic and comfortable for the user. Hard sides will also help; all crew members noted that it was not possible to see through the clear plastic side walls because of creases and wrinkles produced by packing and unpacking the soft Containment Area.

The SoRGE and CRE-1 experiments have shown that soldering and performing electronics repairs are possible in the low gravity, confined environment of a space vehicle or habitat. Improvements in the materials, tools, and training provided to the crew can expand this capability. By providing a robust electronics repair capability, future NASA operation on ISS and missions to the moon and Mars can benefit by reducing the launch and storage costs of full sized replacement or spare ORUs, replacing these items with smaller replacement component and repair tools.

\section{References}

1. Pettegrew, R.D., Easton, J.W., and Struk, P.M., "Repair of Electronics for Long Duration Spaceflight,” 45th AIAA Aerospace Sciences Meeting and Exhibit, Reno, NV, January 8-11, 2007, AIAA-2007-1364.

2. Easton, J.W., Pettegrew, R.D., and Struk, P.M., "Electronic Repair Concepts for Long-Duration Spaceflight,” 45th AIAA Aerospace Sciences Meeting and Exhibit, Reno, NV, January 8-11, 2007, AIAA-2007-545.

3. Pettegrew, R.D., Easton, J.W., Struk, P.M., and Anderson, E.E., "In-Flight Manual Electronics Repair for Deep-Space Missions,” Aerospace Conference, 2007 Institute of Electrical and Electronics Engineers (IEEE), March 3-10, 2007.

4. Struk, P.M., Oeftering, R.C. Easton, J.W., and Anderson, E.E., "Semi-Automated Diagnosis, Repair, and Rework of Spacecraft Electronics," 46th AIAA Aerospace Sciences Meeting and Exhibit, Reno, NV, January 7-10, 2008, AIAA-2008-1130.

5. Easton, J.W., Struk, P.M., Funk, G.P., Latta, G.S., Ganster, A.W., Estes, B.E., Recommendations for Enabling Manual Component Level Electronic Repair for Future Space Missions, NASA Technical Memorandum, in-preparation.

6. Easton, J.W., Struk, P.M., and Rotella, A., "Imaging and Analysis of Void Defects in Solder Joints Formed in Reduced Gravity Using High-Resolution Computed Tomography,” 46th AIAA Aerospace Sciences Meeting and Exhibit, Reno, NV, January 7-10, 2008, AIAA-2008-0824.

7. Watson, J.K., Struk, P.M., Pettegrew, R.D., and Downs, R.S., "Experimental Investigation of Solder Joint Defect Formation and Mitigation in Reduced-Gravity Environments," AIAA Journal of Spacecraft and Rockets, Vol. 44, No. 1 (Jan-Feb 2007), pp. 174-182.

8. Pettegrew, R.D., Struk, P.M., Watson, J.K., Haylett, D.R., and Downs, R.S., "Gravitational Effects on Solder Joints,” Welding Journal, 2003, pp. 44-48.

9. Struk, P.M., Pettegrew, R.D., Downs, R.S., and Watson, J.K., "The Effects of an Unsteady Reduced Gravity Environment on the Soldering Process," 42nd AIAA Aerospace Sciences Meeting and Exhibit, Reno, NV, January 5-8, 2004, AIAA-2004-1311 and NASA/TM-212946, 2004.

10. Soldered Electrical Connections. NASA Technical Standard NASA-STD-8739.3, 1997.

11. Abramoff, M.D., Magelhaes, P.J., Ram, S.J., “Image Processing with ImageJ,” Biophotonics International, Vol. 11, No. 7 (2004), pp. 36-42.

12. Chapra, Steven C., and Canale, Raymond P., Numerical Methods for Engineers, 2nd Ed., McGrawHill, Inc., New York, 1988, pp. 478-489. 


\begin{tabular}{|c|c|c|}
\hline \multicolumn{2}{|c|}{ REPORT DOCUMENTATION PAGE } & $\begin{array}{c}\text { Form Approved } \\
\text { OMB No. 0704-0188 }\end{array}$ \\
\hline \multicolumn{3}{|c|}{ 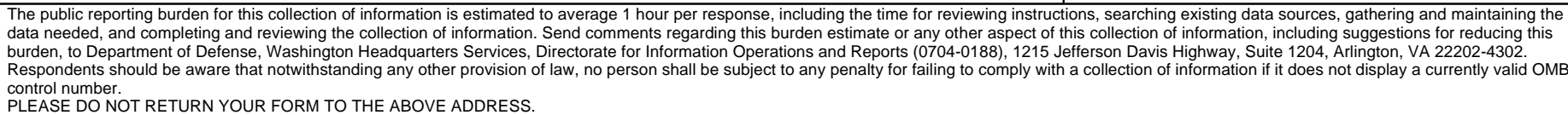 } \\
\hline $\begin{array}{l}\text { 1. REPORT DATE (DD-MM-YYYY) } \\
01-02-2010\end{array}$ & $\begin{array}{l}\text { 2. REPORT TYPE } \\
\text { Technical Memorandum }\end{array}$ & 3. DATES COVERED (From - To) \\
\hline \multirow{3}{*}{\multicolumn{2}{|c|}{$\begin{array}{l}\text { 4. TITLE AND SUBTITLE } \\
\text { Current Space Station Experiments Investigating Component Level Electronics Repair }\end{array}$}} & 5a. CONTRACT NUMBER \\
\hline & & 5b. GRANT NUMBER \\
\hline & & 5c. PROGRAM ELEMENT NUMBER \\
\hline \multirow{3}{*}{\multicolumn{2}{|c|}{$\begin{array}{l}\text { 6. AUTHOR(S) } \\
\text { Easton, John, W.; Struk, Peter, M. }\end{array}$}} & 5d. PROJECT NUMBER \\
\hline & & 5e. TASK NUMBER \\
\hline & & $\begin{array}{l}\text { 5f. WORK UNIT NUMBER } \\
\text { WBS 431767.04.01.03 }\end{array}$ \\
\hline \multicolumn{2}{|c|}{$\begin{array}{l}\text { 7. PERFORMING ORGANIZATION NAME(S) AND ADDRESS(ES) } \\
\text { National Aeronautics and Space Administration } \\
\text { John H. Glenn Research Center at Lewis Field } \\
\text { Cleveland, Ohio 44135-3191 }\end{array}$} & $\begin{array}{l}\text { 8. PERFORMING ORGANIZATION } \\
\text { REPORT NUMBER } \\
\text { E-17119 }\end{array}$ \\
\hline \multirow{2}{*}{\multicolumn{2}{|c|}{$\begin{array}{l}\text { 9. SPONSORING/MONITORING AGENCY NAME(S) AND ADDRESS(ES) } \\
\text { National Aeronautics and Space Administration } \\
\text { Washington, DC 20546-0001 }\end{array}$}} & $\begin{array}{l}\text { 10. SPONSORING/MONITOR'S } \\
\text { ACRONYM(S) } \\
\text { NASA }\end{array}$ \\
\hline & & $\begin{array}{l}\text { 11. SPONSORING/MONITORING } \\
\quad \text { REPORT NUMBER } \\
\text { NASA/TM-2010-216071; AIAA-2009- } \\
6798\end{array}$ \\
\hline \multicolumn{3}{|c|}{$\begin{array}{l}\text { 12. DISTRIBUTION/AVAILABILITY STATEMENT } \\
\text { Unclassified-Unlimited } \\
\text { Subject Categories: 33, 38, and } 12 \\
\text { Available electronically at http://gltrs.grc.nasa.gov } \\
\text { This publication is available from the NASA Center for AeroSpace Information, 443-757-5802 }\end{array}$} \\
\hline
\end{tabular}

\section{SUPPLEMENTARY NOTES}

\section{ABSTRACT}

The Soldering in a Reduced Gravity Experiment (SoRGE) and Component Repair Experiment (CRE)-1 are tests performed on the International Space Station to determine the techniques, tools, and training necessary to allow future crews to perform manual electronics repairs at the component level. SoRGE provides information on the formation and internal structure of through-hole solder joints, illustrating the challenges and implications of soldering in reduced gravity. SoRGE showed a significant increase in internal void defects for joints formed in low gravity compared to normal gravity. Methods for mitigating these void defects were evaluated using a modified soldering process. CRE-1 demonstrated the removal, cleaning, and replacement of electronics components by manual means on functional circuit boards. The majority of components successful passed a post-repair functional test demonstrating the feasibility of component-level repair within the confines of a spacecraft. Together, these tasks provide information to recommend material and tool improvements, training improvements, and future work to help enable electronics repairs in future space missions.

\section{SUBJECT TERMS}

Soldering; Microgravity; International Space Station; Solders; Replacing; Circuit boards; Space missions

\begin{tabular}{|c|c|c|c|c|c|}
\hline \multicolumn{3}{|c|}{ 16. SECURITY CLASSIFICATION OF: } & \multirow{2}{*}{$\begin{array}{l}\text { 17. LIMITATION OF } \\
\text { ABSTRACT } \\
\text { UU }\end{array}$} & \multirow{2}{*}{$\begin{array}{l}\text { 18. NUMBER } \\
\text { OF } \\
\text { PAGES } \\
22\end{array}$} & \multirow{2}{*}{$\begin{array}{l}\text { 19a. NAME OF RESPONSIBLE PERSON } \\
\text { STI Help Desk (email:help@sti.nasa.gov) } \\
\text { 19b. TELEPHONE NUMBER (include area code) } \\
\text { 443-757-5802 }\end{array}$} \\
\hline $\begin{array}{l}\text { a. REPORT } \\
\text { U }\end{array}$ & $\begin{array}{l}\text { b. ABSTRACT } \\
\mathrm{U}\end{array}$ & $\begin{array}{l}\text { c. THIS } \\
\text { PAGE } \\
\text { U }\end{array}$ & & & \\
\hline
\end{tabular}



